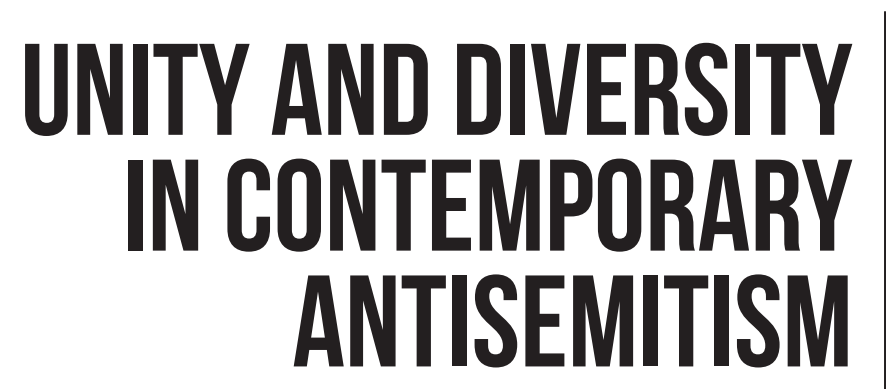

The Bristol-Sheffield Hallam Colloquium on Contemporary Antisemitism 


\section{Antisemitism Studies}

Series Editor: David Patterson (University of Texas at Dallas)

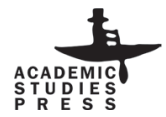




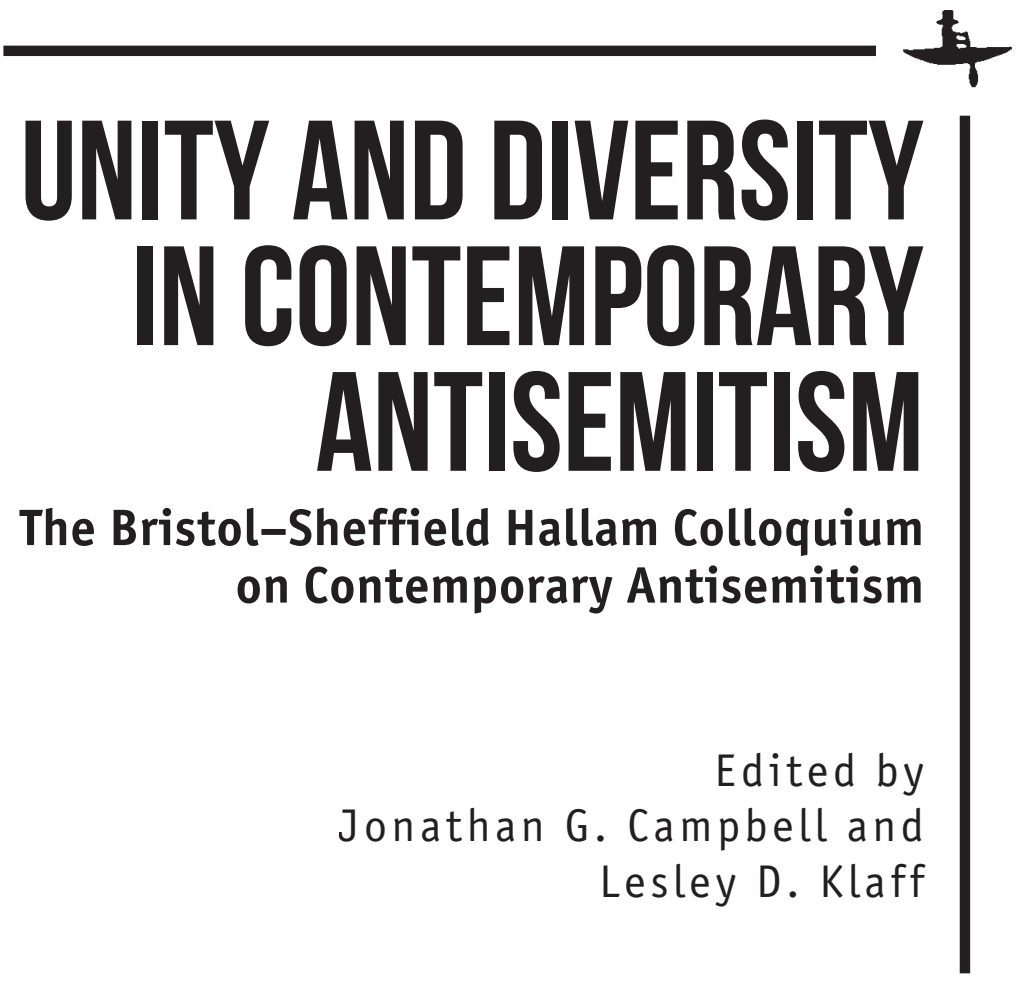


Library of Congress Cataloging-in-Publication Data

Names: Campbell, Jonathan G. (Jonathan Goodson), 1964- editor. | Klaff, Lesley D., editor. | Bristol-Sheffield Hallam Colloquium on contemporary antisemitism (2015: Bristol (England))

Title: Unity and diversity in contemporary antisemitism : the

Bristol-Sheffield Hallam Colloquium on contemporary antisemitism / edited by Jonathan G. Campbell and Lesley D. Klaff.

Description: Boston : Academic Studies Press, 2019. | Series: Antisemitism studies | Includes index. |

Identifiers: LCCN 2019019115 (print) | LCCN 2019019834 (ebook) | ISBN 9781618119674 (ebook) | ISBN 9781618119667 (hardcover)

Subjects: LCSH: Antisemitism--Congresses.

Classification: LCC DS145 (ebook) | LCC DS145 .U538 2019 (print) | DDC 305.892/4--dc23

LC record available at https://lccn.loc.gov/2019019115

(C)Academic Studies Press, 2019

ISBN 9781618119667 (hardback)

ISBN 9781618119674 (electronic)

Book design by PHi Business Solutions

Cover design by Ivan Grave

Published by Academic Studies Press

1577 Beacon Street

Brookline, MA 02446, USA

press@academicstudiespress.com

www.academicstudiespress.com 
Dedicated to the memory of

Professor Robert Fine

1945-2018 
